\title{
Effectiveness of an Educational Program on Nurses' Knowledge about Communicable Diseases Control in Al-Nassiriyah City Hospitals
}

\author{
Talal Mohammed Yousef ${ }^{1}$, Wissam Jabbar Qassim², Zahid Jassim Mohammed ${ }^{3}$ \\ ${ }^{1}$ M.Sc. Student, University of Baghdad, College of Nursing, Community Health Nursing Department, Iraq, ${ }^{2}$ Assist. \\ Professor PhD, University of Baghdad, College of Nursing, Community Health Nursing Department, Iraq, ${ }^{3}$ Assist. \\ Professor Basic science Department, College of Nursing, University of Baghdad, Baghdad City, Iraq
}

\begin{abstract}
Communicable diseases are an illness that is transmitted from a person, animal, or inanimate source to another person either directly, with the assistance of a vector or by other means. Communicable diseases are a major cause of mortality and morbidity in emergencies, and particularly in complex emergencies, where collapsing health services and disease control programs. They are the basic level of infectious pathogens control precautions which are to be used, as a minimum, in the care of all patients. A quasi-experimental design (descriptive study) used to guide this study; it was applied by use of pretest-posttest approach for two groups of samples (study and control) Non- probability (purposive) sample of (80) nurses who are working in Al-Nasiriyah city hospitals.

The findings of the current study revealed that there are highly statistically significant differences in posttest. The study concludes that there is poor and low level of knowledge assessment among the participants toward communicable diseases control at the pre-test in the both group. The results show after the implementation of educational program high level of nurses' knowledge for (post-test I and post-test II) for the study group regarding communicable diseases control. The study concludes there were no significant association between nurses' knowledge and their socio demographic characteristics includes: age; gender; level of education and years of experience. The study recommends of the providing an educational and training program periodically for nurses in order to enhancement the level of their knowledge regarding communicable diseases control.
\end{abstract}

Keywords: Effectiveness of an educational program, nurses> knowledge,communicable diseases control.

\section{Introduction}

Communicable diseases are an illness that is transmitted from a person; animal or inanimate source to another person either directly, with the assistance of a vector or by other means. Communicable diseases cover a wider range than the person to person transmission of communicable diseases ${ }^{[1]}$.

In the fall of 2002, the WHO program on communicable diseases in complex emergencies coordinated the compilation of the communicable disease profile for Iraq. This profile highlighted the most prevalent risks for public health and included a communicable disease toolkit, including rapid health assessment forms, morbidity and mortality surveillance forms, case definition for priority diseases, and guidelines for case-management and outbreak control ${ }^{[2]}$.

Communicable diseases are a major cause of mortality and morbidity in emergencies, and particularly in complex emergencies, where collapsing health services and disease control programs, poor access to health care, malnutrition, interrupted supplies and logistics, and poor coordination among the various agencies providing health care often coexist. The main causes of morbidity and mortality in emergencies conditions are diarrheal diseases, acute respiratory infections, and measles in areas where it is endemic, malaria. Other communicable diseases, such as epidemic meningococcal disease, Tuberculosis, relapsing fever, and Typhus, have also 
caused large epidemics among emergency-affected populations $^{[3]}$.

World Health Organization (2012), an annual report which stated that the importance of communicable diseases control has increased in recent years due to increased travel, trade, migration and emergence of new infections. In addition to the chronic challenges of weak health systems, inadequate commitment and financing for communicable diseases control have resulted in delay to achievement of regional targets. Several countries are facing political instability, social unrest, ongoing conflict and insecurity, all of which have an impact on control of communicable diseases. In this section, we address four thematic areas: poliomyelitis eradication; HIV, TB, hepatitis B,C, malaria and tropical diseases; immunization and vaccines ${ }^{[4]}$.

Hospital acquired infection (HAIs) can be defined as an infection acquired in hospital by a patient who was admitted for a reason other than that infection. An infection are occurring in a patient, in a hospital or other health care facility in whom the infection was not present or incubating at the time of admission. This includes infections acquired in the hospital but appearing after discharge, and also occupational infections among staff of the facility ${ }^{[5]}$.

Nurses are health care professionals whose duty it is to protect patients from acquiring infections while hospitalised or while in a health care set up. By maintaining an infection free environment, the patient's recovery will be promoted and high-quality nursing care will be delivered. Nurses spend most of their time with patients. Therefore, they should have a good level of understanding of the knowledge on prevention and control measures about communicable diseases in health care setups ${ }^{[6]}$.

For example the tuberculosis (TB) is a public health priority in Iraq. The country is among the seven of the countries of the region with a high burden of TB, and accounts for $3 \%$ of the total number of cases. There are an estimated $20000 \mathrm{~TB}$ patients in Iraq. Estimated deaths due to TB are more than 4000 annually. Iraq reported that there are about 8,664 new cases of tuberculosis in 2012 and a prevalence of 73 cases per 100,000 populations. Within Iraq, 180 new cases of multidrug-resistant tuberculosis were confirmed ${ }^{[7]}$.

\section{Method of the Study}

A quasi-experimental design (descriptive study) used to guide this study. It was applied by use of preposttest approach for two groups of samples (case and control) to determine the effectiveness of an educational program on nurses' knowledge about communicable diseases control during period from $15^{\text {th }}$ October 2019 to $20^{\text {th }}$ August 2020.

Non- probability (purposive) sample of (80) nurses who are work -ing in isolation department of AlNasiriyah city hospitals (Al-Hussein Teaching Hospital, Bent Al-Huda Teaching Hospital and Al-Habbobi Teaching Hospital). The sample consists (80) nurses divided into two groups: (40) nurses as study group, which exposed to the health educational program and (40) nurses as control group who not exposed to the health educational program.

Study Instrument: The tool for the study, including four parts, first concerned with the nurse's demographic characteristics like nurses' age, gender, level of education, and marital status. The second part includes a series of MCQ questions covering nurses' knowledge about communicable diseases. The test consists of a list of (20) questions and consists of choices. Third is concerned with data related to the nurses' knowledge toward method of communicable diseases control, which are consist of (15) questions. The fourth part is concerned with data related to the nurses' knowledge toward standard precautions which are consist of (20) questions.

The content validity of the program and the study instruments are determined by the panel of (13) experts, which have more than (7) years' experience in their field to investigate the content of the educational program and the questionnaire about communicable disease control.

Rating and Scoring: The level of knowledge was scored by rating (2) for the correct answer and (1) for the incorrect one, therefore, knowledge rating explained by the following intervals $\mathrm{L}=$ Low level (1-1.33), $\mathrm{M}=$ Moderate level (1.34-1.67), $\mathrm{H}=$ High level (1.68-2). Data of the study were ordered according to three levels of scale (High, Moderate, and Low) early stated which were scored as (2 and 1) for each level respectively. It is classified as scores of response according to the following: 
$\mathrm{L}=$ Low level (1-1.33)

$\mathrm{M}=$ Moderate level (1.34-1.67)

$\mathrm{H}=$ High level (1.68-2)

The Statistical Data Analysis: Data are analyzed through using the program of Statistical Package of Social Sciences (SPSS, Version 21). The following statistical data analysis approaches are used in order to analyze and assess the results of the study.

\section{Results and Discussion}

Socio-demographic characteristics of the present study: The table (1) represents the socio -demographic characteristics of the present study (study and control group). It shows the majority of the study and control sample at the middle age ranged (25 - 29) years. For study group are accounted for (24) nurses with represented of percentage $(45 \%)$, while for control group represent of percentage $(60 \%)$.

The study findings agree with study in Nigeria that indicated about knowledge and application of infectious diseases control measures among primary care workers in Nigeria. It revealed that most participants $(34.2 \%)$ of health care workers were age group $(25-34)^{[8]}$.

This is due to the large number of recent employees in the field of health, as the Ministry of Health is working to employ thousands of nurses' graduates annually from specialized institutes and colleges in the health field, so most ages are from this age group.

In regarding for gender, the table shows that the majority of participants were female for both groups (control and study). Which were represented of percentage $(57.5 \%)$ of all.

The study findings agree with study done in in Nigeria indicated that about knowledge and application of infectious diseases control measures. It revealed that most study sample were female which represented $(76.2 \%){ }^{[9]}$.

Concerning the level of education, the present study shows that (19) of participants, nurses in study group were graduated from nursing institute and represented (47\%). While for control group, also the most were graduated from nursing institute about (24) nurses with percentage $(60 \%)$.
The findings supported study in South Africa of for Nurses' knowledge of tuberculosis, HIV, and integrated $\mathrm{HIV} / \mathrm{TB}$, which revealed that $(54 \%)$ of participants nurses had diploma qualification ${ }^{[10]}$.

Regarding to the marital status, results of study show that the majority of control and study sample (75\%) were married. This results agree with study by

The study findings are similar with study of Yousef in 2019 to implementing the educational program regarding nurses' knowledge about infection control measures and results revealed that majority (68.75\%) were married $^{[11]}$.

Related to the training session, the study findings show that the majority of nurses in study group were $(85 \%)$, while for control were (77.5) have not participated in a formal educational program about communicable diseases control. Lack of access and interest in the training courses leads to poor skills development of nursing staff regarding the communicable diseases control.

The study findings agree with study of Al-Ghamdi in (2011) that show $(57.8 \%)$ of health care workers did not participanted in training course about communicable diseases control. These findings reported that the poor nurses' knowledge related to lack of interest and motivation in participating in training course about communicable diseases control ${ }^{[12]}$.

Concerning the years of experience, the study findings reveals that majority of participants for both group (control and study) have (6-10) years in their experience with percentage (45\%) for control group and $(37.5 \%)$ for study group.

The present results agree with study of Hamid in (2010) who conduct a study to assess Knowledge of infectious diseases and the practice of universal precautions amongst health-care workers in a tertiary hospital in Malaysia. They found the (79\%) of participants have experience in range of (5-9) years ${ }^{[13]}$.

Table(2) shows that distribution of knowledge scores general information on (communicable diseases, method of control, and standard precautions) and indicated was that high level of knowledge related to study group.

Table (3) shows all three posttest nurses' knowledge scores general information on (communicable diseases, 
method of control, and standard precautions) to be significantly higher between the study group and control group.

The study findings supported by study done in Egypt were noted that the effect of educational program for knowledge of nurses for study group at a posttest ${ }^{[14]}$.

Anther study support the present study results, which reported the effect of educational program on nurses' compliance with Universal precautions of infection control and noted high significant differences between study and control group ${ }^{[15]}$.

Before the implementation of the educational program, a pre-test was carried out on study group and results show the level of nurses' knowledge regarding three domains of communicable diseases control was poor.

These results agree with study done in Saudi Arabia. Saudi was reported that nurses had poor knowledge about communicable diseases control ${ }^{[11]}$.

Also, the result is consistent with that findings obtained by Phetlhu in (2018) which revealed that the most nurses have poor knowledge concerning communicable diseases ${ }^{[9]}$

\section{Association between socio-demographic} characteristics and nurses' knowledge: Results of tables (4) showed that there is no statistical significant association between nurses' knowledge and their gender at (pre-test, post-test I and posttest II tests) of educational program follow up ( $p$ value $>0.05$ ), and also there are no differences between mean of knowledge.

The study findings agree with study soudiarab was stated that no significant association between genders of nurses concerning communicable diseases contro ${ }^{[11]}$
Table (4) shows that there is no statistical significant association between nurses' age and their knowledge regarding communicable diseases control.

The findings supported by study of Phetlhu in (2018) who state that there is no is no statistical significant association between nurses' age and their knowledge at $(\mathrm{p} \leq 0.05 \text { value })^{[9]}$.

Additionally, to another study conducted in egipt which noted that there is no significant relationship between nurses' age and their knowledge toward standard precautions and infection control ${ }^{[15]}$.

Table (4) regarding the level of education, it shows there is no signification association between the educational level and nurses' knowledge concerning communicable diseases control.

Results agree with Batranin(2018) conduct a study on nurses' knowledge about standard precautions and reveals that there is no singnificat association between educational level and knowledge ${ }^{[16]}$

Table (4) according to results of this table, there is no significant between experience for nurses' work and their knowledge concerning communicable diseases control ( $\mathrm{p}$ value $>0.05$ )

Results agree with study by Hamid in (2010) about Knowledge of infectious diseases and the practice of universal precautions amongst health-care workers. It noted that no relation between years of experience of health-care workers and their knowledge ${ }^{[12]}$.

Additionally, study in Ninavah Covernorate was showed that there ere no significant statistical differences in post - test scores between nurses' knowledge with regard to their years of employment ${ }^{[17]}$.

Table (1): Distribution of The Study Sample by Socio- Demographic for Study and Control Group

\begin{tabular}{|c|c|c|c|c|c|}
\hline \multirow{2}{*}{ Var. } & \multirow{2}{*}{ Groups } & \multicolumn{2}{|c|}{ Control } & \multicolumn{2}{|c|}{ Study } \\
\hline & & Freq. & $\%$ & Freq. & $\%$ \\
\hline \multirow{4}{*}{ Age Groups } & $20-24$ & 1 & 2.5 & 2 & 5.0 \\
\hline & $25-29$ & 24 & 60.0 & 18 & 45 \\
\hline & $30-34$ & 15 & 37.5 & 18 & 45 \\
\hline & $35-39$ & 0 & 0 & 2 & 5 \\
\hline \multirow{2}{*}{ Gender } & Male & 17 & 42.5 & 17 & 42.5 \\
\hline & Female & 23 & 57.5 & 23 & 57.5 \\
\hline
\end{tabular}




\begin{tabular}{|c|c|c|c|c|c|}
\hline \multirow{2}{*}{ Marital status } & Married & 30 & 75 & 30 & 75 \\
\hline & Single & 10 & 25 & 10 & 25 \\
\hline \multirow{3}{*}{ Educational level } & Nursing secondary school & 11 & 27.5 & 13 & 32.5 \\
\hline & Nursing institute & 24 & 60 & 19 & 47.5 \\
\hline & Nursing college & 5 & 12.5 & 8 & 20 \\
\hline \multirow{2}{*}{ Participating in Training } & Yes & 9 & 22.5 & 6 & 15 \\
\hline & No & 31 & 77.5 & 43 & 85 \\
\hline \multirow{3}{*}{ Years of experience } & 5 and less & 15 & 37.5 & 13 & 32.5 \\
\hline & $6-10$ & 18 & 45 & 15 & 37.5 \\
\hline & $11-16$ & 7 & 17.5 & 12 & 30 \\
\hline \multicolumn{2}{|l|}{ Total } & 40 & 100 & 40 & 100 \\
\hline
\end{tabular}

Freq $=$ frequency, $\%=$ percentages

Table (2) distribution of knowledge levels between the pre and post-test related to study group. (N=40)

\begin{tabular}{|c|c|c|c|c|}
\hline Domains & Periods & Total Mean & SD & Levels \\
\hline \multirow{3}{*}{ Nurses' knowledge about communicable diseases } & Pre & 1.1388 & 0.0964 & Moderate \\
\hline & Post I & 1.9763 & 0.0357 & High \\
\hline & Post II & 2.00 & 0.000 & High \\
\hline \multirow{3}{*}{$\begin{array}{l}\text { Nurses' knowledge about ways to communicable } \\
\text { diseases control }\end{array}$} & Pre & 1.1133 & 0.0882 & Low \\
\hline & Post I & 1.9900 & 0.0241 & High \\
\hline & Post II & 2.00 & 0.000 & High \\
\hline \multirow{3}{*}{ Nurses' Knowledge about Standard Precautions } & Pre & 1.1150 & 0.0622 & Low \\
\hline & Post I & 1.9888 & 0.0211 & High \\
\hline & Post II & 1.9962 & 0.0133 & High \\
\hline \multirow{3}{*}{ OVER ALL } & Pre & 1.1231 & 0.0616 & Low \\
\hline & Post I & 1.9686 & 0.0174 & High \\
\hline & Post II & 1.9978 & 0.0036 & High \\
\hline
\end{tabular}

$\mathrm{SD}=$ standard deviation, $\mathrm{L}=$ low level (1-1.33), $\mathrm{M}=$ moderate level (1.34-1.67), $\mathrm{H}=$ high level (1.68-2).

Table (3) Comparison of Knowledge Scores between the Study and Control Groups at Posttest. ( $=40)$

\begin{tabular}{|c|c|c|c|c|c|c|}
\hline Domains & Group & Total Mean & SD & $\mathbf{t}$ & $\mathbf{P}$ & d.f. \\
\hline \multirow{2}{*}{ Nurses' knowledge about communicable diseases } & Post control & 1.158 & 0.078 & \multirow{2}{*}{57.37} & \multirow{2}{*}{0.00} & \multirow[b]{2}{*}{78} \\
\hline & Post study & 1.976 & 0.036 & & & \\
\hline \multirow{2}{*}{$\begin{array}{l}\text { Nurses' knowledge about ways to communicable } \\
\text { diseases control }\end{array}$} & Post control & 1.157 & 0.112 & \multirow{2}{*}{46.32} & \multirow{2}{*}{0.00} & \multirow[b]{2}{*}{78} \\
\hline & Post study & 1.990 & 0.024 & & & \\
\hline \multirow{2}{*}{ Nurses' Knowledge about Standard Precautions } & Post control & 1.139 & 0.102 & \multirow{2}{*}{51.81} & \multirow{2}{*}{0.00} & \multirow[b]{2}{*}{78} \\
\hline & Post study & 0.989 & 0.021 & & & \\
\hline \multirow{2}{*}{ Over all } & Post control & 1.152 & 0.058 & \multirow{2}{*}{86.14} & \multirow{2}{*}{0.00} & \multirow[b]{2}{*}{78} \\
\hline & Post study & 1.969 & 0.017 & & & \\
\hline
\end{tabular}


Table (4): Association between socio-demographic characteristics group and Knowledge fort the study group at Post -Test

\begin{tabular}{|c|c|c|c|c|c|c|}
\hline Variable & Groups & Freq. & $\%$ & F value & $P$ value & Sig. \\
\hline \multirow{2}{*}{ Gender } & Male & 17 & 42.5 & \multirow{2}{*}{-0.087} & \multirow{2}{*}{0.931} & \multirow{2}{*}{ N.S } \\
\hline & Female & 23 & 57.5 & & & \\
\hline \multirow{4}{*}{ Age Groups } & $20-24$ & 2 & $5.0 \%$ & \multirow{4}{*}{0.271} & \multirow{4}{*}{0.846} & \multirow{4}{*}{ N.S } \\
\hline & $25-29$ & 18 & $45.0 \%$ & & & \\
\hline & $30-34$ & 18 & 45 & & & \\
\hline & $35-39$ & 2 & 5 & & & \\
\hline \multirow{4}{*}{ Educational level } & Total & 40 & 100 & \multirow{4}{*}{1.179} & \multirow{4}{*}{0.319} & \multirow{4}{*}{ N.S } \\
\hline & Nursing secondary school & 13 & 32.5 & & & \\
\hline & Nursing institute & 19 & 47.5 & & & \\
\hline & Nursing college & 8 & 20 & & & \\
\hline \multirow{3}{*}{ Years of experience } & 5 and less & 13 & 32.5 & \multirow{4}{*}{0.025} & \multirow{4}{*}{0.975} & \multirow{4}{*}{ N.S } \\
\hline & $6-10$ & 15 & 37.5 & & & \\
\hline & $11-16$ & 12 & 30 & & & \\
\hline \multicolumn{2}{|l|}{ Total } & 40 & 100 & & & \\
\hline
\end{tabular}

Frequency, $\mathrm{F}=$ Fisher test, $\%=$ Percentage, $\mathrm{P}$.value, NS: Non Significant at $\mathrm{P}>0.05$

Ethical Clearance: The Research Ethical Committee at scientific research by ethical approval of both environmental and health and higher education and scientific research ministries in Iraq

Conflict of Interest: The authors declare that they have no conflict of interest.

Funding: Self-funding

\section{Reference}

1. Webber R, editor. Communicable disease epidemiology and control: a global perspective. Cabi; 2009.

2. Wilson K, Fidler DP, McDougall CW, Lazar H. Establishing public health security in a postwar Iraq: constitutional obstacles and lessons for other federalizing states. Journal of Health Politics, Policy and Law. 2009 Jun 1;34(3):381-99.

3. Jafari N, Shahsanai A, Memarzadeh M, Loghmani A. Prevention of communicable diseases after disaster: A review. Journal of research in medical sciences: the official journal of Isfahan University of Medical Sciences. $2011 \mathrm{Jul}$;16(7):956.

4. World Health Organization. Communicable diseases. Annual report by World Health
Organization. 2012.

5. Monegro AF, Muppidi V, Regunath H. Hospital acquired infections. Stat Pearls [Internet]. 2020 Aug 11.

6. Chitimwango PC. Knowledge, attitudes and practices of nurses in infection prevention and control within a tertiary hospital in Zambia (Doctoral dissertation, Stellenbosch: Stellenbosch University).

7. World Health Organization. Global tuberculosis report 2013. World Health Organization; 2013.

8. Aigbiremolen AO, Duru CB, Awunor NS, Abejegah C, Abah SO, Asogun AD, Eguavoen OL. Knowledge and application of infectious diseases control measures among Primary Care workers in Nigeria: the Lassa fever example. International Journal of Basic, Applied and Innovative Research. 2012;1(4):122-9.

9. Phetlhu DR, Bimerew M, Marie-Modeste RR, Naidoo M, Igumbor J. Nurses' knowledge of tuberculosis, HIV, and integrated HIV/TB care policies in rural Western Cape, South Africa. Journal of the Association of Nurses in AIDS Care. 2018 Nov 1;29(6):876-86.

10. Yousef YE, Elashir UM, Mahmoud SR, Maghraby 
$\mathrm{N}$. The effect of nursing educational program on knowledge and practice of nurses regarding infection control measures for children under hemodialysis. Egyptian Nursing Journal. 2019 Jan $1 ; 16(1): 1$.

11. Al-Ghamdi AS, Kabbash IA. Awareness of healthcare workers regarding preventive measures of communicable diseases among Hajj pilgrims at the entry point in Western Saudi Arabia. Saudi Med J. 2011 Nov 1;32(11):1161-7.

12. Hamid MZ, Aziz NA, Anita AR, Norlijah O. Knowledge of blood-borne infectious diseases and the practice of universal precautions amongst healthcare workers in a tertiary hospital in Malaysia. Southeast Asian journal of tropical medicine and public health. 2010 Sep 1;41(5):1192.

13. Galal YS, Labib JR, Abouelhamd WA. Impact of an infection-control program on nurses' knowledge and attitude in pediatric intensive care units at Cairo University hospitals. The Journal Of The Egyptian Public Health Association. 2014 Apr 1;89(1):22-8.
14. Fayed NM, Hanan T, Elbahnasawy TH, Omar KT. Effect of Instructional program on nurses compliance with Universal precautions of infection control. International Journal of Novel Research in Healthcare and Nursing. 2016;3(1):81-92.

15. Gawad A. Assessment of knowledge about standard precautions and nosocomial infection among nurses working in hospitals of Sana'a city, Yemen. International Journal of Caring Sciences. 2017 Jan $1 ; 10(1)$.

16. Batran A, Ayed A, Salameh B, Ayoub M, Fasfous A. Are standard precautions for hospitalacquired infection among nurses in public sector satisfactory?. Archives of Medicine and Health Sciences. 2018 Jul 1;6(2):223.

17. Wahab MM, Taha TH. The Effect of an Educational Program on Nurses' Knowledge about Hepatitis B Virus (HBV) in NinavahCovernorate Hospitals. Mosul Journal of Nursing. 2016;4(2):81-7. 